\title{
ENSINO DO TÊNIS E A PRÁTICA PEDAGÓGICA DOS PROFESSO- RES
}

\author{
Guy Ginciene \\ Universidade Federal do Rio Grande do Sul, Porto Alegre, Rio Grande do Sul, Brasil \\ Affonso Manoel Righi Lang \\ Universidade Estadual Paulista "Júlio de Mesquita Filho", Rio Claro, São Paulo, Brasil \\ Larissa Rafaela Galatti \\ Universidade Estadual de Campinas, Campinas, São Paulo, Brasil \\ Fernando Jaime González \\ Universidade Regional do Noroeste do Estado do Rio Grande do Sul, Ijuí, Rio Grande do Sul, Brasil \\ Suraya Cristina Darido \\ Universidade Estadual Paulista "Júlio de Mesquita Filho", Rio Claro, São Paulo, Brasil
}

\begin{abstract}
Resumo
O objetivo deste artigo foi o de analisar a prática pedagógica das aulas de tênis de um clube tradicional no ensino da modalidade, a partir do discurso e da prática de professores experientes na modalidade. Para isso, a pesquisa foi estruturada em três partes: aproximação com o campo de pesquisa, observações sistemáticas das aulas de tênis e entrevistas semiestruturadas com os professores. Constatou-se que as aulas de tênis têm características tradicionais centradas no ensino do gesto técnico descontextualizado da situação de jogo, embora os professores tenham esboçado no nível do discurso algumas compreensões sobre as novas proposições para tratar esta modalidade.
\end{abstract}

Palavras-chave: Educação Física. Pedagogia do esporte. Tênis. Ensino. Treinador.

\section{TEACHING TENNIS AND THE PEDAGOGICAL PRACTICE OF COACHES}

\begin{abstract}
The aim of this paper was to analyze the pedagogical practice of tennis classes through the speech and the practice of some experience teachers. To reach that, this research was organized in 3 parts: approach in the research place; observation of the tennis classes; interview with the tennis teachers. It was found that the tennis lessons have traditional approaches centered on the technical gesture, which is decontextualized of the game situation, although in teachers speeches, they seems to know some insights of the new propositions of tennis teaching.
\end{abstract}

Keywords: Physical Education. Sport pedagogy. Tennis. Teaching. Coach.

\section{ENSEÑANZA DEL TENIS Y LA PRÁTICA PEDAGÓGICA DE LOS TREINADORES}

\section{Resumen}

El objetivo de este artículo fue analizar la práctica pedagógica de las clases de tenis de un club tradicional en la enseñanza del deporte, a partir del discurso y de la práctica de profesores con 
experiencia en el deporte. Para eso, la investigación se estructuro en tres partes: aproximación al campo de investigación, observaciones sistemáticas de las clases de tenis y entrevistas semiestructuradas con los profesores. Se constató que las clases de tenis tienen características tradicionales centradas en la enseñanza del gesto técnico descontextualizado de la situación del juego, aunque los profesores hayan descrito en el nivel del discurso algunas comprensiones sobre las nuevas propuestas para trabajar el tenis.

Palabras clave: Educación física. Pedagogía del deporte. Tenis. Enseñanza.Entrenador.

\section{Introdução}

A tradição pedagógica do ensino do tênis parece não ser diferente dos demais jogos esportivos, particularmente dos esportes coletivos (GALATTI et al., 2014). O desenvolvimento da técnica acaba sendo o foco principal de grande parte das aulas, ainda que a lógica interna da modalidade exija um tratamento diferenciado (GONZÁLEZ; FRAGA, 2012).

Estudos sobre o tênis no país apontam que a tradição privilegia métodos de ensino centrados na repetição de movimentos (BOLONHINI, 2009; GARCÍA, 2009; VALENTINI et al., 2009). García (2009) aponta que, nesse tipo de método, "o técnico se limita a explicar e demonstrar a tarefa" e "a orientar a prática dos alunos de forma a fazê-los imitarem essa demonstração" (p. 46). Não bastasse isso, o ensino desses golpes se baseia em uma "estratégia analítica de um componente por meio da fórmula da repetição" (p. 46).

Unierzyski e Crespo (2007) observam que o foco principal no ensino tradicional do tênis não possibilita o entendimento do jogo. Os autores reforçam que grandes atletas, não só do tênis, como também de outros esportes, aprenderam os aspectos técnicos e táticos sozinhos, sem os treinadores, por meio de tentativa e erro. $\mathrm{O}$ que se apresenta com um grande desperdício de tempo e energia, dada a importância da aprendizagem significativa no esporte.

Na mesma linha, Crespo e Reid (CRESPO; REID, 2005) apresentam críticas ao modelo tradicional de ensino desta modalidade. Na perspectiva dos autores, as metodologias centradas exclusivamente na aprendizagem técnica fazem com que os alunos dominem os golpes durantes as situações de exercícios e treinos - caracterizados pela pouca variabilidade nas decisões que devem ser tomadas (chamadas de situações fechadas) -, porém, nas situações de jogo (abertas), cuja variabilidade é maior, eles não compreendem ou não sabem qual decisão tomar em cada momento.

Neste contexto, conhecer as maneiras como os professores conduzem a prática pedagógica do tênis permite mapear o momento atual, bem como melhor compreender os processos que facilitam e/ou dificultam a transformação dessa prática. Dessa forma, o objetivo deste artigo foi o de analisar a prática pedagógica dos professores de tênis de campo de um clube tradicional no ensino da modalidade a partir do discurso e da prática de professores ${ }^{1}$ experientes na modalidade, em uma cidade de porte médio do interior de São Paulo.

\section{Metodologia}

A metodologia utilizada na pesquisa foi de natureza qualitativa (TRIVIÑOS, 1987), estruturada em três etapas: (a) aproximação com o campo de pesquisa; (b) observações sistemáticas das aulas de tênis em um clube do interior paulista; (c) entrevistas semiestruturadas com os três professores participantes do estudo.

\footnotetext{
${ }^{1}$ Embora exista uma tendência para que a palavra "treinadores" seja utilizada para se referir àqueles que ensinam o tênis em clubes e academias, assim como utilizado na literatura internacional, optamos neste artigo pelo termo "professores", por ser essa a forma como são conhecidos os sujeitos participantes desta pesquisa em seu ambiente de trabalho.
} 
A partir da natureza qualitativa, a pesquisa se caracteriza como um estudo de caso do tipo descritivo. $\mathrm{O}$ estudo de caso visa qualificar as características encontradas como forma de compreensão do fenômeno, partindo da interação do pesquisador com os diferentes personagens pertencentes ao ambiente social investigado (YIN, 2003).

A aproximação com o clube e a observação sistemática das aulas possibilitaram a compreensão do contexto em que as aulas são organizadas, sistematizadas e implementadas pelos professores. Posteriormente, foram realizadas entrevistas semiestruturadas com os professores, com o objetivo de identificar a visão deles sobre suas aulas e comparar posteriormente com os dados colhidos nas observações sistemáticas, bem como fazer um retrato do perfil de cada um dos participantes.

Esse conjunto de técnicas metodológicas permitiu a interpretação da complexidade de um único caso, facilitando a exploração em profundidade de uma variedade de situações (SPARKES; SMITH, 2014).

Após o ingresso ao campo - negociado com dirigente e professores, foram observadas 11 aulas (dos diferentes níveis de aprendizado do tênis), somando-se as aulas particulares e em grupo. Durante as aulas, registraram-se a sequência didática, as estratégias pedagógicas e os materiais utilizados pelos três participantes da pesquisa.

\section{Resultados e discussão}

Nesta parte do artigo, são apresentados os dados coletados nas observações sistemáticas das aulas de tênis e das entrevistas semiestruturadas realizadas com os professores. Para isso, primeiramente é apresentado o perfil do clube e dos professores participantes da pesquisa e, depois, os resultados das observações e entrevistas, que foram divididos em três categorias de análise: rituais da aula, metodologia de ensino e relação professor-aluno.

\section{Perfil do clube e dos professores}

O local escolhido para o desenvolvimento da pesquisa foi um clube tradicional de uma cidade de porte médio do interior do estado de São Paulo. O clube, fundado na década de 1960, foi o primeiro da cidade, sendo sempre uma instituição de referência em seu tipo. Atualmente, a instituição conta com mais de dez quadras de tênis e já revelou atletas de destaque nacional na modalidade.

Os três professores analisados e entrevistados jogavam tênis antes de começarem a dar aula. Por outro lado, os três iniciaram a dar aulas antes de alguma formação específica em tênis. Os professores ministravam aulas há 30 (professor 1), 18 (professor 2) e 14 anos (professor 3), respectivamente.

Apenas o professor 3, o mais jovem, tinha formação em Educação Física. Este, durante a graduação, teve a oportunidade de cursar uma disciplina específica de esportes de raquete, o que não é muito comum entre os cursos de Educação Física (CORTELA et al., 2012; DIAS et al., 2002), contudo, na perspectiva do entrevistado, a disciplina não contribuiu para sua formação como professor da modalidade.

Os professores afirmaram ter realizado diversos cursos de tênis, embora há tempos não participam de nenhum. O último realizado por um dos professores foi em 2007. 


\section{Categorias de análise}

\section{Rituais da aula}

Durante as observações, não foi percebida qualquer indicação ou explicação do professor sobre o objetivo específico da aula, como treinar uma intenção tática ou melhorar o aspecto técnico de algum golpe. Diferente disso, o início dos trabalhos, como as demais atividades desenvolvidas nas aulas, parecia seguir um ritual, que se repetia independentemente do número, da idade ou do nível técnico/tático dos alunos.

Nem todas as aulas foram iguais, mas seguiram certa sequência. Começavam por um aquecimento em quadra reduzida (utilizando o espaço da área de saque apenas) ou por $d^{2}$ rills ${ }^{2}$ de esquerda e direita do fundo de quadra. Seguiam uma parte central de drills para trabalhar os golpes de fundo e depois os de rede. Finalizavam trabalhando-se um pouco do saque e realizando algum tipo de jogo. Vale lembrar que, das 11 aulas observadas, cinco não tiveram treinos de saque e seis não tiveram jogo.

Por meio das entrevistas, pode-se perceber que, em relação à organização e à estruturação das aulas, os três seguem a mesma sequência. Especificamente, o professor 3 comenta que o padrão seguido começa por uma conversa, segue com um aquecimento, o trabalho da técnica, uma parte técnico-tática (tentando criar situações reais de jogo, posicionamento, movimentação, etc.) e por fim um jogo. No entanto, nas aulas acompanhadas desse professor, a parte técnico-tática não foi observada. A repetição da mesma rotina de treino para os diferentes grupos de alunos evidencia uma característica tradicional que se espera superar com metodologias contemporâneas: para os professores estudados, é o aluno quem se adapta ao esporte, e não o esporte que precisa receber um tratamento pedagógico para se adequar às características e aos objetivos dos alunos (GALATTI et al., 2008; 2014).

O professor 3 ainda mencionou três tipos de treino: fechado, semiaberto e aberto, os quais ele procura inserir em suas aulas. O fechado seria o lançamento de bolas para que os alunos rebatam e treinem os golpes $(d r i l l s)$. O semiaberto é o momento em que o professor, além de lançar bolas, também participa, devolvendo as bolas rebatidas pelos alunos. Já o treinamento aberto é mais voltado ao jogo e normalmente destinado ao final da aula. Vale destacar aqui que, ao menos nas aulas observadas, o treinamento "fechado" foi o que prevaleceu. O "semiaberto" apareceu somente em uma aula e por pouco tempo. Já o treinamento "aberto" consistiu apenas no jogo nos moldes de uma partida oficial e não em adaptações dos jogos como sugerido pelas propostas compreensivas (MITCHELL; OSLIN; GRIFFIN, 2013; THORPE; BUNKER; ALMOND, 1986), evidenciando que os professores não têm conhecimento específico sobre como superar as abordagens tradicionais de ensino do tênis.

Diversas são as propostas elaboradas para superar o ensino tradicional do tênis, que passam tanto por formas metodológicas em que a dimensão tática e técnica dos jogos são articuladas durante o ensino (CRESPO, 1996; ITF, 2009; MITCHELL; OSLIN; GRIFFIN, 2013; TENNANT, 2013), como pela proposição de contextos de aprendizagem mais significativos em que a centralidade do trabalho não consista em imitar o professor (SIEDENTOP; HASTIE; MARS, 2011; VALENTINI et al., 2009). Os resultados das pesquisas sobre o assunto são bastante categóricos acerca das vantagens de ensinar o tênis, como os demais jogos esportivos, a partir de aproximação compreensiva ou tática, tanto no que se refere ao desempenho (BURROWS; ABBEY, 1986; GUBACS-COLLINS, 2007; TURNER; MARTINEK, 1995; ZETOU et al., 2014) como à motivação dos alunos para a prática (BURROWS;

\footnotetext{
${ }^{2}$ Drills é a denominação que ganham os exercícios realizados em aulas de tênis, nos quais o professor, munido de uma grande quantidade de bolas, lança-as em uma sequência predeterminada para que os alunos possam rebatê-las, de forma repetitiva, sem que o professor ou alguém as devolva.
} 
ABBEY, 1986; DOOLITTLE, 1986; GUBACS-COLLINS, 2007; TURNER; MARTINEK, 1995; ZETOU et al., 2014).

Dessa forma, a ideia é que o ensino do tênis seja baseado, num primeiro momento, na compreensão do jogo para um posterior desenvolvimento dos aspectos técnicos de forma contextualizada. Trata-se de levar o aluno a entender primeiramente o que fazer (tática), para que, depois, de forma mais significativa, compreenda o como fazer (técnica) (THORPE; BUNKER; ALMOND, 1986).

Neste tópico, vale destacar a fala do professor 3, quando ele explica a sequência das aulas. Essa fala vai contra o treinamento mais tradicional, centrado na técnica, e se aproxima de metodologias mais atuais de ensino: "Primeiro faz a pessoa que está começando a jogar tênis a gostar de jogar tênis, ela tem que jogar, se ela não jogar, ela acaba parando, não adianta você ficar repetindo só direita, só direita...", porém não se refletiu na forma que o trabalho foi efetivamente orientado durante as aulas observadas.

Dois dos entrevistados, o professor 1 e o professor 3, relataram que não organizam suas aulas baseadas nas que tiveram quando treinavam. Mesmo assim, descreveram que os drills, utilizados em suas aulas, também eram utilizados por seus professores. A diferença elencada em relação à aula deles e à de seus mentores era que, antes, existia muito mais repetição, algo que, segundo os entrevistados, eles procuram não reproduzir em suas aulas. Essa concepção fica clara na resposta do professor 3, quando indagado sobre suas aulas quando aluno: “...era muito chato cara, era muito repetitivo, só repetição, só repetição, só repetição [...] meia hora de direita, meia hora de esquerda....praticamente a aula toda já estava acabando e a gente já estava cansado para jogar".

Outro depoimento que merece destaque é o do professor 2, que contradiz a ideia de que seria necessário ensinar de uma forma diferente daquela em que ele aprendeu. Ao mencionar os métodos de tênis que conhecia, ele afirmou, diversas vezes, ter conseguido tornar-se um professor de tênis pela forma como aprendeu, como se vê nas frases a seguir: "...eu tive uma boa base com ele, de aprender a ensinar a mecânica assim" [...] "Aprendi muito com ele, com os métodos que usava". Essa constatação reforça o entendimento de Reverdito, Scaglia e Paes (2009), segundo a qual parte das dificuldades da Educação Física em incorporar novas formas de ensinar os esportes se vincula com o fato de que muitos professores propõem suas aulas com base nas suas experiências como atletas e não nos conhecimentos técnico-científicos produzidos na área.

Isso reforça a importância que a experiência prévia do sujeito tem na sua prática docente: a exemplo do observado em outras modalidades, o modelo de treinamento que o professor viveu como atleta no passado ou o estilo de treino de seu mentor (treinador experiente que aconselha o professor de esporte no início da carreira) influencia fortemente a prática pedagógica (BRASIL et al., 2016; RAMOS et al., 2014). Desta forma, mais do que novos conhecimentos, aos professores adeptos do estilo tradicional faz falta uma reflexão sobre a sua prática, sobre as influências que a construíram e sobre como modificá-las de acordo com as necessidades dos praticantes (MILISTETD et al., 2015).

\section{Metodologia de ensino}

A maior parte das aulas observadas no trabalho esteve centrada em drills. Esse tipo de trabalho se caracteriza como de situação fechada, ou seja, quando o exercício não apresenta uma variabilidade na execução, nem tomada de decisão, ambos os aspectos próprios do jogo de tênis (CRESPO; REID, 2005). Mais do que isso, essa forma de organização metodológica das aulas de tênis contraria a lógica interna da modalidade, que é a de passar a bola para o outro lado da quadra de forma que o adversário não consiga ou tenha dificuldades em devolvê-la (GONZÁLEZ; DARIDO; OLIVEIRA, 2014; PARLEBAS, 2001). Nos drills, os alunos 
recebem bolas lançadas de forma cooperativa e rebatem para o "nada", como se jogassem sozinhos. Isto se alinha com os métodos mais tradicionais de ensino, já que está centrado, quase que exclusivamente, na aprendizagem do padrão de movimento (BOLONHINI, 2009; CRESPO; REID, 2005; GARCÍA, 2009; GRECO; SILVA; ABURACHID, 2009; UNIERZYSKI; CRESPO, 2007; VALENTINI et al., 2009).

Outro formato de exercício observado durante as aulas foi aquele em que os alunos trocam bolas entre si ou com o professor. A troca de bolas é um tipo de tarefa que se aproxima um pouco mais das situações de jogo, quando comparada com os drills, contudo sem a imprevisibilidade característica do jogo. Quando os alunos realizam esses exercícios, não recebem as bolas com a mesma velocidade, altura, profundidade e efeito padronizados, como acontece nos drills, já que as bolas são devolvidas pelo colega de diferentes formas. Por esse motivo, as características de rebatidas já são mais próximas do que acontece no jogo, pelo menos no que se refere à variabilidade do movimento. Apesar disso, é preciso lembrar que esse tipo de tarefa é de caráter cooperativo, já que o propósito da ação é dar continuidade à troca de bolas e, para tal, o aluno busca rebater a bola de tal forma que seja fácil ao colega retorná-la.

Em outras palavras, essa tarefa não apresenta uma característica específica do jogo de tênis: a oposição. Durante uma partida de tênis, o objetivo é rebater a bola nos espaços vazios da quadra para dificultar a devolução do adversário e, assim, ganhar o ponto e não pela ideia de facilitar a ação do adversário. Ainda assim, vale relatar que esta tarefa mais próxima do jogo foi proposta apenas em duas das 11 aulas observadas.

Nesse sentido, é preciso ressaltar que, durante as aulas observadas, os alunos tiveram oportunidade de resolver situações de jogo - decidir o que fazer antes de fazer - apenas quando da realização de jogos formais, o que ocupou tempo bastante reduzido (aproximadamente 16\% do tempo total de aula) de apenas cinco das 11 aulas acompanhadas. Tarefas estruturadas por meio de jogos em quadras reduzidas e com objetivos táticos claramente definidos, bem como ataque, defesa e contra-ataque nas situações de jogo do tênis - sugestões estas próprias de propostas compreensivas do ensino do tênis (ITF, 2009; MITCHELL; OSLIN; GRIFFIN, 2013) -, não foram observadas em nenhuma das aulas.

Já nas entrevistas, os professores demonstraram não conhecer especificamente as novas metodologias de ensino do tênis, apesar de terem revelado em outros momentos que acreditam em um formato de ensino do tênis que se assemelha, ao menos na ideia, das novas metodologias. No entanto, durante esse momento particular da entrevista, isso não ficou claro. O professor 1, por exemplo, mencionou a existência de vários métodos, mas não exemplificou um em específico com nomes e detalhes. O Play and Stay é conhecido de forma superficial pelos entrevistados, que só lembraram dessa proposta de ensino quando o pesquisador o mencionou, como nesse exemplo: "Ah sim, esse é um... ah esse é um método sim, legal, que eu uso sim, verdade, bem lembrado".

Ainda falando sobre o Play and Stay, o professor 2 entra num assunto mais específico da metodologia de ensino que ele utiliza: "[...] eu tenho usado esse método [Play and Stay] e depois se eu vejo que o aluno tem dificuldade, se ele não tem muita habilidade, daí eu vou para um método mais analítico". Perguntado sobre qual seria o método analítico, o mesmo professor responde dessa forma: "[...] tem aluno que aprende melhor demonstrando, tem aquele que você tem que... só lançar bola pra ele e ele vai aprender... ou se não, você vai ter que fazer por partes mesmo, bem analítico mesmo, mostrar etapa por etapa da mecânica [...]”. Percebe-se o pouco conhecimento do professor acerca das possibilidades metodológicas para o ensino do tênis.

O professor 3 também mencionou essas formas de ensino: "Então, existe um treinamento global e um treinamento específico, se eu não estou enganado. $\mathrm{O}$ treinamento global seria você pegar o aluno e ensinar... não isolar apenas um golpe.... pegar um forhand, 
um backhand, um voleio, um smash, um saque, talvez não na primeira aula já, mas na primeira, na segunda e pegar e já ensinar seu aluno todos os golpes, diferente do treinamento específico, que você repete muito um forhand, por exemplo, que na minha opinião torna-se uma aula maçante".

Ainda nas entrevistas, percebeu-se que a concepção de treinamento tático dos professores passa pela exposição verbal de informações sobre esse tema e não pela estruturação de atividades que ofereçam a oportunidade de resolução de problemas táticos específicos do tênis de forma intencional. Duas falas dos professores apontam nesse sentido, como é o caso da resposta do professor 3, ao ser indagado sobre a forma que ele insere na parte tática em suas aulas: "tento criar situações reais de jogo... tá... e falar de movimentação... é... posicionamento, movimentação, deslocamento do adversário...”. O professor 2 também reforça esse aspecto: “Às vezes eu só aqueço meu aluno e já caio para o jogo já, dependendo do nível do aluno... pra gente conversar de tática de jogo, não ficar só na técnica, conversar um pouquinho de tática, porque é importante a gente conversar isso com o aluno".

Perguntado sobre qual forma o professor 2 utiliza para trabalhar a parte tática, ele menciona que é com "bola viva" (situação de jogo) e ainda complementa sobre o formato das aulas, que muitas vezes não favorece o trabalho dos aspectos táticos: "A gente tem uma cultura aqui no clube, ainda, de aula particular... aí a parte tática não fica tão real com o professor e aluno... eu estou tentando agora montar grupos para que alunos treinem entre eles...e treinem a parte tática entre eles, porque daí não fica tão real professor e aluno, porque o professor é muito facilitador".

Esses dados revelam dois pontos relacionados ao ensino do tênis, de forma particular sobre o ensino dos aspectos táticos do jogo. Um deles está relacionado à fala do professor, quando admite que os aspectos táticos do jogo são mais importantes para a competição que para a aprendizagem ou a prática de lazer. Aparentemente, na sua concepção, essa dimensão é própria do esporte de alto rendimento e não do nível com o qual ele trabalha e relata uma máxima tradicional que se repete no ensino dos jogos esportivos: a de que o treino tem um objetivo e o jogo, ou competição, outro; ou seja: treino é treino, jogo é jogo (GALATTI et al., 2014; 2016). O outro ponto diz respeito ao formato do treino tático, que, segundo diversos autores (ITF, 2009; MITCHELL; OSLIN; GRIFFIN, 2013; THORPE; BUNKER; ALMOND, 1986), deveria se basear em jogos, jogos reduzidos, situações de jogo e até mesmo em questionamentos durante as tarefas para desenvolver as intenções táticas, ao contrário do que foi observado nas aulas e nas entrevistas dos professores participantes desta pesquisa.

Cruzando as informações das entrevistas e das observações, percebeu-se que, embora os professores tenham mencionado a existência de muitas metodologias de ensino, não citaram nenhuma em específico. Apesar disso, um dos professores, em sua entrevista, esboçou conhecimento sobre o treinamento analítico e global, apontando a preferência pela utilização desse último. Esse apontamento vai ao encontro das principais abordagens atuais do ensino do tênis, de fazer com que os alunos joguem primeiro e depois desenvolvam os aspectos técnicos. No entanto, não foi possível observar exercícios mais contextualizados e que tivessem por objetivo desenvolver as intenções táticas do tênis e a compreensão do jogo, como apontam Unierzyski e Crespo (2007), ao afirmarem que, se os técnicos seguissem as metodologias mais modernas do ensino do tênis, a primeira parte desenvolvida deveria ser as habilidades cognitivas, de entendimento do jogo e de solução de problemas, para desenvolver as habilidades técnicas em seguida.

Diante dessa divergência entre o discurso e a prática e analisando novamente as entrevistas dos três professores, percebe-se que els não demonstram conhecimentos sobre formas de organizar metodologicamente suas aulas. Ou seja, os professores têm uma ideia geral e superficial sobre a importância de se ensinar a técnica depois da compreensão do jogo, 
mas não demonstram ter conhecimentos específicos sobre como fazer isso. Para eles, jogo é o produto final do ensino e não um recurso de aprendizagem. No discurso dos professores 2 e 3 , fica claro que a ideia que eles têm sobre as formas de se trabalhar com as novas abordagens é o "treinamento semiaberto" (professor 2) e a "bola viva" (professor 3), que nada mais é do que trocar bola com o aluno. No entanto, como já mencionado anteriormente, esse tipo de treino não respeita a oposição que todo jogo de tênis apresenta Mesmo parecendo óbvia e evidente essa característica, este é um dos pontos mais importantes para a compreensão dessa nova organização metodológica.

É por esse aspecto que são baseadas as abordagens que utilizam os jogos para conscientização tática. Nenhum dos professores apresentou, tanto no discurso quanto na prática, estratégias de utilização dos jogos em espaços reduzidos e com regras simplificadas para ensinar os alunos aspectos derivados da lógica interna do tênis, como por exemplo: criar espaços na quadra adversária para o ataque, ganhar o ponto, defender seus espaços na quadra (MITCHELL; OSLIN; GRIFFIN, 2013).

\section{Relação professor-aluno}

As informações transmitidas aos alunos durante as aulas foram poucas e nem sempre relacionadas ao tênis. Em uma das aulas, o que chamou a atenção foi a ausência completa de informações sobre o que seria feito. Apesar disso, os alunos não demonstraram dificuldades em executar os exercícios, o que aponta que a sequência deles era rotineira.

As informações repassadas para cada um dos exercícios (baseados em drills) eram previamente informadas pelas tarefas e golpes, como nesse caso: "agora vai trocar a tarefa, vai ser uma bola de direita, uma de esquerda, um slice e um voleio" (professor 2). Outras formas apareceram, mas sempre atreladas a características de determinados movimentos técnicos do tênis.

Assim, as informações apresentadas pelos professores, majoritariamente, estiveram centradas na descrição dos aspectos técnicos, sem contemplar conceitos orientados à compreensão do jogo de maneira global.

Em síntese, não foi registrado qualquer conceito tático durante as aulas, como orientações sobre como criar espaços na quadra adversária para atacar ou mesmo sobre como defender os espaços do seu lado.

Além disso, questões histórico-culturais sobre a modalidade apareceram poucas vezes e, quando surgiram, foram mais por iniciativa dos alunos que dos professores. A temática nesse caso sempre esteve relacionada aos torneios e aos jogos que ocorriam durante a semana. Isso reforça a ideia de que esse tipo de conteúdo é pouco desenvolvido nas aulas de esportes (MACHADO; GALATTI; PAES, 2014; 2015).

Se, por um lado, as explicações dos exercícios ocorriam a cada troca de tarefa, foram verificadas poucas intervenções visando motivar os alunos durante a realização das atividades. Aqui, cabe destacar que, em diversos momentos das aulas, os professores comentavam que determinado aluno não estava motivado, contudo, não foram verificadas intervenções para tentar reverter o quadro. Nesse sentido, se destaca a fala do professor 2, durante uma aula em que um dos alunos demonstrava estar motivado: "isso aí, assim que tem que ser, se o aluno está motivado, eu fico com o dobro de motivação".

Em relação às correções, estas ocorreram durante os exercícios, por meio de orientações verbais como: "armar melhor", "pular mais leve", "tirar da rede", entre outros. Além disso, o professor 2, em alguns momentos, interrompia o exercício para demonstrar o movimento e explicar alguma técnica, utilizando, assim, mais uma forma para que os alunos compreendessem os detalhes do gesto praticado. 
Nesse sentido, coerente com a visão de ensino desse professor - centrada no ensino das habilidades da modalidade -, a maior parte das correções foi realizada de acordo com as dificuldades técnicas que os alunos apresentavam durante a aula. Os outros dois professores (1 e 3), diferente do anterior, normalmente não faziam intervenções diretas para corrigir a técnica, apenas falavam como deveria ser executada enquanto a atividade seguia sendo desenvolvida.

Aqui vale salientar uma diferença entre as aulas individuais e em grupos. Nas primeiras, os professores realizavam um maior número de intervenções com correções técnicas, quando comparadas com as segundas. Em uma das aulas individuais, as correções técnicas foram excessivas, visto que o aluno tinha apenas oito anos e ainda estava iniciando na modalidade. Essa aula pode ter sofrido influência da presença dos pesquisadores, já que o professor 2, ao final da aula, dirigiu-se para o observador dizendo: "Essa aula foi boa... essa foi do jeito que eu queria!". No entanto, mesmo que o professor tenha modificado sua aula por conta da presença do pesquisador, é preciso observar sua crença de que uma boa aula deve conter um elevado número de intervenções e informações técnicas, se aproximando, assim, das abordagens tradicionais para o ensino do tênis (CRESPO; REID, 2005; GARCÍA, 2009; UNIERZYSKI; CRESPO, 2007; VALENTINI et al., 2009).

\section{Considerações finais}

Diante de tudo que foi apresentado nas três categorias anteriores, foi possível constatar nas entrevistas que os professores manifestam preocupação em transcender a proposição de aulas centradas nos aspectos técnicos do tênis e na repetição de exercícios, bem como em procurar que a iniciação dos alunos seja de forma global, fazendo com que eles joguem antes de começar a desenvolver as técnicas específicas da modalidade. No entanto, ainda durante as entrevistas, foi possível detectar que os professores têm uma ideia superficial das novas abordagens de ensino, faltando a eles um conhecimento mais específico sobre novas formas de organizar metodologicamente as aulas, de maneira a formar um jogador consciente taticamente, com boas tomadas de decisões, que compreenda a lógica de funcionamento do jogo e consequentemente possa superar o ensino tradicional. Não à toa a observação das aulas indicou que o ensino desenvolvido apresenta características tradicionais: centrado no ensino das técnicas, com a proposição de tarefas majoritariamente descontextualizadas do jogo (fechadas) e feedback focado nos detalhes do gesto esportivo. Mais do que isso, não foram observadas atividades que procurassem abordar aspectos conceituais histórico-críticos do tênis.

Portanto, constatou-se, nesta pesquisa, que os professores não têm conhecimentos específicos e mais aprofundados sobre as novas abordagens de ensino dos esportes, que consequentemente deixam as aulas com características tradicionais, revelando a necessidade de revisar as estratégias metodológicas com o propósito de potencializar a aprendizagem da modalidade e o envolvimento dos alunos com a prática.

Apesar disso, existe uma divergência entre o discurso e a prática pedagógica do professor, já que mesmo superficialmente os professores afirmam ser importante superar os modelos tecnicistas, mas suas práticas não condizem com esse discurso. Várias são as hipóteses para essa divergência. Uma delas pode estar relacionada à falta de conhecimento específico e aprofundado sobre essa reformulação metodológica necessária às aulas de tênis e que consequentemente dificulta e impede uma mudança em sua prática.

Dessa forma, para que ocorra uma mudança, é preciso que o professor passe por um processo de capacitação e até mesmo de reformulação de sua rotina de trabalho, já que, para atender às novas abordagens e reorganizar metodologicamente suas aulas, os professores certamente precisarão de tempo para organizar e planejar as aulas, algo pouco difundido na cultura esportiva, visto que grande parte dos professores de tênis tem grandes cargas horárias 
de trabalho, sobrando pouco ou quase nenhum tempo para o seu desenvolvimento profissional.

\section{Referências}

BOLONHINI, S. Z. Pedagogia do Esporte e a iniciação ao tênis de campo: um estudo nos principais clubes de São Paulo. [s.l.]: UNICAMP, 2009.

BRASIL, V. Z. et al. As ações pedagógicas para a intervenção do treinador de surf. Movimento, v. 22, n. 2, p. 403-416, 2016.

BURROWS, L.; ABBEY, W. A teacher's teactions. In: THORPE, R.; BUNKER, D.;

ALMOND, L. (Ed.). Rethinking games teaching. Leicstershire: Univesity of Loughborough, 1986, p. 45-51.

CORTELA, C. C. et al. Iniciação esportiva ao tênis de campo: um retrato do programa Play and Stay à luz da Pedagogia do Esporte. Revista da Faculdade de Educação Física da UNICAMP, v. 10, n. 2, p. 214-234, 2012.

CRESPO, M. Mini-tenis: un medio para el aprendizaje del tenis. Apunts: Educación física y deportes, n. 44, p. 42-50, 1996.

CRESPO, M.; REID, M. M. Metodología de la enseñanza del tenis para principiantes. Revista Stadium, n. 192, 2005, p. 28-54.

DIAS, J. M. et al. O ensino-aprendizagem de tênis nos cursos de Educação Física. In: JORNADA INTERNACIONAL DE TREINAMENTO E ORGANIZAÇÃO. Anais... Florianópolis: UFSC/NETEC, 2002, p. 105-107.

DOOLITTLE, S. Reflecting on an innovation. In: THORPE, R.; BUNKER, D.; ALMOND, L. (Ed.). Rethinking games teaching. Leicstershire: Univesity of Loughborough, 1986, p. 36-38.

GALATTI, L. R. et al. Pedagogia do Esporte: procedimentos pedagógicos aplicados aos jogos esportivos coletivos. Conexões, v.6, p. 397-408, 2008.

GALATTI, L. R. et al. Pedagogia do Esporte: tensão na ciência e o ensino dos Jogos Esportivos Coletivos. Revista da Educação Física/UEM, v. 25, n. 1, p. 153, 2014.

GALATTI, L. R. et al. Coaches perceptions of youth players development in a professional soccer club in Brazil paradoxes between the game and those who play. Sports Coaching Review, july 2016, p. 174-185.

GARCÍA, J. P. F. Métodos de ensino e destrezas de comunicação no ensino do tênis. In: BALBINOTTI, C. et al. In: O ensino do tênis: novas perspectivas de aprendizagem. Porto Alegre: Artmed Editora, 2009.

GONZÁLEZ, F. J.; DARIDO, S. C.; OLIVEIRA, A. A. B. Esportes de marca e com rede divisória ou muro/parede d rebote. Maringá: Eduem, 2014. 
GONZÁleZ, F. J.; FRAGA, A. B. Afazeres da Educação Física na escola: planejar, ensinar, partilhar. Erechim: Edelbra, 2012.

GRECO, P. J.; SILVA, S. A. DA; ABURACHID, L. M. C. Iniciação esportiva universal: uma escola da bola aplicada ao tênis. In: BALBINOTTI, C. et al. O ensino do tênis: novas perspectivas de aprendizagem. Porto Alegre: Artmed Editora, 2009.

GUBACS-COLLINS, K. Implementing a tactical approach through action research. Physical Education \& Sport Pedagogy, v. 12, n. 2, p. 105-126, 2007.

ITF, I. T. F. Manual de play tennis. London: International Tennis Federation, 2009.

MACHADO, G. V.; GALATTI, L. R.; PAES, R. R. Pedagogia do Esporte e o referencial histórico-cultural: interlocução entre teoria e prática. Pensar a Prática, v. 17, n. 1, p. 414430, 2014.

MACHADO, G. V.; GALATTI, L. R.; PAES, R. R. Pedagogia do Esporte e projetos sociais: interlocuções sobre a prática pedagógica. Movimento, v. 21, n. 2, p. 405-418, 2015.

MILISTETD, M. et al. A aprendizagem profissional de treinadores esportivos: desafios da formação universitária em Educação Física. Pensar a prática, Goiânia, v. 18, n. 4, p. 982994, 2015.

MITCHELL, S. A.; OSLIN, J. L.; GRIFFIN, L. L. Teaching sport concepts and skills. 3. ed. [s.1.]: Human Kinetics, 2013.

PARLEBAS, P. Juegos, deporte y sociedades: Léxico de praxeología motriz. Barcelona: Editorial Paidotribo, 2001.

RAMOS, V. et al. As crenças sobre o ensino dos esportes na formação inicial em Educação Física. Revista da Educação Física/UEM, v. 25, n. 2, p. 231, 2014.

REVERDITO, R. S.; SCAGLIA, A. J.; PAES, R. R. Pedagogia do esporte : panorama e análise conceitual das principais abordagens. Motriz, v. 15, p. 600-610, 2009.

SIEDENTOP, D.; HASTIE, P.; MARS, H. VAN DER. Complete guide to sport education. 2. ed. [s.1.]: Human Kinetics, 2011.

SPARKES, A. C.; SMITH, B. Qualitative research methods in sport, exercise and health. London: Routledge, 2014.

TENNANT, M. Principios del aprendizaje aplicados a los adultos. Coaching \& Sport Science Review, 2013.

THORPE, R.; BUNKER, D.; ALMOND, L. Rethinking games teaching. Leicstershire: Univesity of Loughborough, 1986.

TRIVIÑOS, A. N. S. Introdução à pesquisa em ciências sociais: a pesquisa qualitativa em educação. São Paulo: Atlas, 1987.

TURNER, A.; MARTINEK, T. J. Teaching for understanding: a model for improving decision making during game play. Quest (National Association for Physical Education in 
Higher Education), v. 47, n. 1, p. 44-63, 1995.

UNIERZYSKI, P.; CRESPO, M. Review of modern teaching methods for tennis. (Análisis de los métodos actuales de enseñanza del tenis.). RICYDE. Revista internacional de ciencias del deporte, v. 3, p. 1-10, 2007.

VALENTINI, N. C. et al. Considerações sobre o desenvolvimento e a aprendizagem motora em crianças. In: BALBINOTTI, C. et al. O ensino do tênis: novas perspectivas de aprendizagem. Porto Alegre: Artmed Editora, 2009.

YIN, R. K. Case study research: design and methods. Thousand Oaks: Sage, 2003.

ZETOU, E. et al. The effect of game for understanding on backhand tennis skill learning and self-efficacy improvement in elementary students. Procedia - Social and Behavioral $\begin{array}{llllll}\text { Sciences, } & \text { v. } & 152, & \text { p. } & 765-771, & 2014 .\end{array}$

Recebido em: 10/02/2017

Revisado em: 09/08/2017

Aprovado em: 04/09/2017

Endereço para correspondência:

guy_ginciene@ hotmail.com

Guy Ginciene

Universidade Federal do Rio Grande do Sul

Av. Paulo Gama, 110 - Farroupilha

Porto Alegre - RS, 90040-060 